\title{
The Role of Sociocultural Theory in L2 Empirical Research
}

\author{
Sean Hughes \\ Teachers College, Columbia University
}

\section{INTRODUCTION}

Second language acquisition (SLA) is a complex, interdisciplinary field of study which has its roots in subjects as varied as cognition and psychology to social applications and actions in anthropology and sociology (Han \& Nassaji, 2019). One of the oldest and most influential ideas in SLA comes from the sociocultural perspective and, in particular, the work of Soviet psychologist Lev Vygotsky. Nearly a century ago, Vygotsky attempted to connect the seemingly disparate areas of society, culture, and cognition in his unifying, wide-angle theory called Sociocultural Theory (SCT).

This theory argues that cognition is not a purely psychological process but is instead a process mediated by cultural artifacts and activities such as interaction (Vygotsky, 1986). While this theory aims to provide a wide-ranging, general theory for human learning and cognition, it has been adapted in SLA in a few key areas, in particular, the Zone of Proximal Development (ZPD). Vygotsky claimed that learning is essentially a mediated process, and that a learner's abilities at any point in time can be understood as three layers: (1) what the learner can do unaided, (2) what the learner can do with mediation, and (3) what the learner cannot do, even with mediation. It is this middle tier of ability, i.e., what the learner can do with mediation, that Vygotsky identified as the Zone of Proximal Development (Vygotsky, 1986). This theoretical notion of ZPD and the use of mediation in the form of social interaction to increase learning and expand individual knowledge is the basis of each study reviewed for this paper.

\section{ANALYSIS OF EMPIRICAL STUDIES}

The studies chosen for this forum center around Sociocultural Theory generally and focus on the Zone of Proximal Development specifically. While each study takes a different approach to connect language learning to the Vygotskian concept of mediation in the ZPD, they are all unified in their adoption of Vygotsky's (1986) definitions of ZPD and mediation. While each of the accounts varies slightly on what qualifies as mediation, the analyses sampled for this paper all use the same basis for their findings, making each a unique yet similar example of the impact of SCT on SLA research.

In the first study sampled for this paper, Aljaafreh and Lantolf (1994) studied the effects of negative feedback on the microgenetic development, i.e., the series of changes in a learner's ability, knowledge, or understanding over a short period of time, of adult English learners. These researchers argued that the tailoring and graduating of feedback to learners' ZPD by a tutor assists learning, thus allowing for self-correction. The authors explored the impact of writing corrections in a one-to-one setting with three English language learners at the University of

\footnotetext{
(C) 2021 Hughes. This is an open access article distributed under the terms of the Creative Commons Attribution License, which permits the user to copy, distribute, and transmit the work provided that the original authors and source are credited.
} 
Delaware. Over the course of a semester, the interaction served to improve the writing of the participants, according to the authors' ZPD-based analysis.

The authors first discussed the process of learning and how feedback guides that process, citing research from DeKeyser (1993), Spada and Lightbown (1993), and Carroll and Swain (1993). However, the majority of the literature reviewed in this research focused on the ZPD and the collaboration constructed between teacher and student. The authors quoted Vygotsky directly, highlighting that a "fundamental tenet of sociocultural theory is its thesis that human mental activity is essentially a mediated process" (Aljaafreh \& Lantolf, 1994, p. 467). Aljaafreh and Lantolf went on to connect ZPD to genetic law of cultural development, wherein language first appears between people, then again on an individual level, which the authors called "appropriation" (Aljaafreh \& Lantolf, 1994, p. 467). The researchers then explained the process of microgenesis, highlighting Vygotsky's use of the process in his research into ZPD. Finally, Aljaafreh and Lantolf defined ZPD in terms of their research focus, outlining the roles of learning in terms of Vygotsky's research with young children developing cognition and learning, summing up their argument that " $[\mathrm{t}]$ he $\mathrm{ZPD}$ is the framework, par excellence, which brings all of the pieces of the learning setting together" (1994, p. 468). Tying this to their research, Aljaafreh and Lantolf noted that "[d]iscovering the potential developmental level of the novice and providing appropriate help accordingly is at its core - a dialogic activity that unfolds between more capable and less capable individuals" (Aljaafreh \& Lantolf, 1994, p. 468).

This research claimed that "[e]ffective error correction and language learning depend crucially on mediation provided by other individuals" (1994, p. 480). Audio and transcripts from discussions between the tutors and students in the study were used to analyze psychological and linguistic development longitudinally over the course of a semester. The authors went on to present a regulatory scale based on a continuum of corrective strategies used by the tutor, varying in levels of implicitness or explicitness. According to the analysis of the microgenesis in ZPD with each student, there was a clear progression of linguistic ability, including acquisition of word forms as well as pragmatic usage. Learners received a balance of graded implicit and explicit correction that the learners developed an ability to self-repair, resulting in a diminished provision of corrective feedback over time. The authors concluded that great individual learner discrepancies exist and encourage peer-to-peer studies to analyze the effect of such interaction on the ZPD and learning, which we see in the next study.

Although the mediating "other" in Vygotskian theory is often interpreted as an advanced speaker who is paired with a more novice learner, Swain and Lapkin (2002) interpreted the "other" providing guidance in the ZPD as a peer or classmate. The authors argued that in metatalk used in the classroom, peers can serve "concurrently [as] experts and novices" (2002, p. 286). According to their study, this problem-solving and collaborative peer dialogue advanced learning and, with support from previous research, can be implemented as a tool of mediation, thereby resulting in construction of individual knowledge. Swain and Lapkin summarized Vygotsky's notions of mediation in the form of a more knowledgeable other in their introduction, setting the theoretical stage on which their research is formulated. The authors addressed other related research in SCT, notably by Tudge (1990) and Wells (2000), stating, "[h]owever in recent years, the idea that peer-peer interaction may also foster learning has been advanced" instead of a more knowledgeable other (Swain \& Lapkin, 2002, p. 286). In explaining their qualitative research design and application, Swain and Lapkin used Lantolf's research on internalization and metatalk influencing the language learning process. Other previous studies 
were cited as evidence upon which the authors base their analysis and conclusions, but Vygotsky remained the center of the theoretical underpinnings.

Swain and Lapkin (2002) observed seventh-grade students in a French immersion class in Toronto, Canada working on tasks explicitly chosen for their ability to increase collaborative talk, namely dictogloss and jigsaw. The students first wrote a story in the target language collaboratively, then a native-speaker reformulated version of the story was introduced, and finally students were tasked with individually rewriting with this input. The researchers focused on the dialogue between the students and analyzed it as a tool for mediating their learning by sketching out the steps taken in the task, as discussed in the dialogue. This analysis allowed the authors to trace the connection between the mediation of the other in the ZPD to the individual knowledge gained at the end of the task.

Although both students followed two thirds of the corrections made in the reformulation by the French native speaker, they rejected roughly one third of the suggestions, retaining their own forms. Of these non-corrected forms, approximately 75 percent were acceptable alternatives to the changes proposed by the native speaker. Each could clearly be connected to a period of what the authors call "talking it through," whereby the learners discussed the comments and negotiated what each knew or what the other knew, which appeared to have led to internalization of jointly constructed knowledge (Swain \& Lapkin, 2002, p. 298). In short, learning took place between the learners and not just with the feedback from the instructor, supporting Vygotsky's claim that social interaction is key to learning and constructing individual knowledge.

In the final study sampled, Erlam, Ellis, and Batstone (2013) used Aljaafreh and Lantolf (1994) as a basis for replicating the aforementioned research results. However, the authors opted to analyze the effects of corrective feedback on learners from not only a sociocultural framework, but also a cognitive-interactionist framework in order to compare the two approaches. In short, the cognitive-interactionist approach views language as an individual cognitive effort. This stands in opposition to SCT, which views cognition as a result of interaction. University participants from various L1 backgrounds were recruited in New Zealand, with a total of 15 learners observed for the study. In their attempt to replicate the 1994 study, the researchers used Aljaafreh and Lantolf's regulatory scale to provide feedback to seven of the learners. The remaining eight learners received only explicit feedback, in line with cognitiveinteractionist literature, which implies that explicit feedback is more effective than implicit (Erlam et al., 2013, p. 258).

Erlam et al. introduced a multi-pronged approach for their mixed methods study. First, the authors introduced the cognitive-interactionist approach and theoretical foundations, citing Long (2006). Then, previous research, namely Carroll (2001), was cited as bases for quantitative and qualitative analysis. Next, they introduced the sociocultural paradigm, briefly citing Vygotsky's theoretical notions of ZPD, and mentioning Lantolf's (2000) as well as Aljaafreh and Lantolf's (1994) studies as a foundation for conducting qualitative analysis. Aljaafreh and Lantolf's 1994 study was specifically cited for the definition of learning "in terms of whether the extent of the other-regulation needed for a learner to self-correct [is] reduced over time" (Erlam et al., 2013, p. 258). The authors then introduced the role of corrective feedback in language pedagogy, citing researchers such as Harmer (1983), Brumfit (1977), and Scrivener (2005) to outline the benefit of feedback and its role in learning.

The researchers observed both groups of learners and monitored their progress over two classes and two feedback conferences roughly one month apart, and compared learning based on the repetition of errors which were previously corrected by the instructor. Both groups were 
given identical texts for each class, and then asked to reconstruct the text within one hour. The only methodological difference between the two groups was the type of feedback given. The researchers analyzed video and transcripts of feedback discussions, and then aggregated data for corrections qualitatively for each group. In order to determine what was happening on an individual level, two participants, one from each group, were randomly singled out for further analysis.

The findings were mixed; the first finding was that Aljaafreh and Lantolf's (1994) graduated feedback was more successful than explicit feedback at allowing learners to notice errors and self-correct. However, Erlam et al. (2013) found no evidence of consistent learning over time with this SCT method, noting that the same learners made repeated mistakes with identical structures despite correction. The researchers noted that a probable reason for explaining the difference between their findings and those of Aljaafreh and Lantolf was the method of analysis. While Aljaafreh and Lantolf used a microgenetic qualitative analysis for analysis, Erlam et al. used a systematic method of quantitative analysis in addition to a qualitative analysis of the protocols (Erlam et al., 2013, p. 266). Overall, Erlam et al. found it impossible to determine which type of feedback was more effective but found that explicit feedback was more efficient.

\section{DISCUSSION AND CONCLUSION}

One noteworthy facet of these seemingly disparate studies was the way in which the researchers determined the connection between theory and their design. While the first two studies focused on qualitative analyses of the type of talk and interaction in the learning process, the third study used qualitative analysis with the addition of a quantitative analysis. Erlam et al. (2013) noted that the broad claims of Sociocultural Theory and its applications in SLA must be analyzed in a more systematic way than merely looking at the type of talk and the immediate results, which was convincing. Although all three initial studies used the same theoretical foundations from Vygotsky's Sociocultural Theory and specifically the notion of the Zone of Proximal Development, there was an immense variation in the methods used to analyze the data. Seeing various analyses employed to verify results was far more persuasive than employing only one method.

While these reports were intriguing, they were far from unanimous in their findings or analyses. In order for SCT to be more readily applied in SLA, there needs to be more uniformity in the approach to data analysis. If each researcher interprets results in their own way, as we see in these various studies, there will be little useful data to replicate and use in further studies. The use of a top-down, multi-pronged, multi-disciplinary approach would better reflect the true nature of SCT.

A final critique from this review is that nearly all of the available research came from just two authors. It was hard to find research which did not come from either Lantolf or Poehner, which severely limited the research available for analysis. As well, every study done after Aljaafreh and Lantolf (1994) referenced their framework and based their methods on these researchers. Hopefully more researchers will take up SCT in SLA and conduct empirical studies which can bolster the field and theory in the future.

Clearly, SCT has had a valuable impact on SLA. For one, the research reviewed here has directly led to developments in dynamic assessment (DA). Researchers such as Antón (2009) have operationalized DA by framing its application in Vygotsky's own words, supported by 
predecessors such as Aljaafreh and Lantolf. Following this, Poehner (2009), expanded the concept to group dynamic assessment (G-DA), which focuses on constructing activities tailored to a collective ZPD. Most recently, Yang and Qian (2020) investigated the concept of computerized dynamic assessment (CDA) in the evaluation of second language performance. These more quantitative analyses lend credence to SCT and highlight the salient position which this theory has in SLA and will likely continue to hold for the foreseeable future.

\section{REFERENCES}

Aljaafreh, A., \& Lantolf, J. P. (1994). Negative feedback as regulation and second language learning in the Zone of Proximal Development. The Modern Language Journal, 78, 465483. https://doi.org/10.2307/328585

Antón, M. (2009). Dynamic assessment of advanced second language learners. Foreign Language Annals, 42(3), 576-598. https://doi-org.tc.idm.oclc.org/10.1111/j.19449720.2009.01030.x

Brumfit, C. (1977). Correcting written work. Modern English Teacher, 5, 22-23.

Carroll, S. (2001). Input and evidence: The raw material of second language acquisition. John Benjamins.

Carroll, S., \& Swain, M. (1993). Explicit and implicit negative feedback: An empirical study of the learning of linguistic generalizations. Studies in Second Language Acquisition, 15, 35786.

DeKeyser, R. M. (1993). The effect of error correction on L2 grammar knowledge and oral proficiency. Modern Language Journal, 77, 501-514.

Erlam, R., Ellis, R., \& Batstone, R. (2013). Oral corrective feedback on L2 writing: Two approaches compared. System, 41, 257-268. https://doi.org/10.1016/j.system.2013.03.004

Han, Z., \& Nassaji, H. (2019). Introduction: A snapshot of thirty-five years of instructed second language acquisition. Language Teaching Research, 23(4), 393-402. https://doi.org/10.1177/1362168818776992

Harmer, J. (1983). The practice of English language teaching. Longman.

Lantolf, J. (2000). Second language learning as a mediated process. Language Teaching, 33, 7996.

Long, M. (2006). Problems in SLA. Lawrence Erlbaum.

Poehner, M. E. (2009). Group dynamic assessment: Mediation for the L2 classroom. TESOL Quarterly, 43(3), 471-491.

Scrivener, J. (2005). Learning teaching: A guidebook for English language teachers. Macmillan Education.

Spada, N., \& Lightbown, P. M. (1993). Instruction and the development of questions in L2 classrooms. Studies in Second Language Acquisition, 15, 205-224.

Swain, M., \& Lapkin, S. (2002). Talking it through: Two French immersion learners' response to reformulation. International Journal of Educational Research, 37, 285-304. https://doi.org/10.1016/S0883-0355(03)00006-5

Tudge, J. (1990). Vygotsky, the zone of proximal development and peer collaboration: implications for classroom practice. In L. C. Moll (Ed.), Vygotsky and education (pp. 155172). Cambridge University Press.

Vygotsky, L. S. (1986). Thought and language. Cambridge, MA: MIT Press. 
Wells, G. (2000). Dialogic inquiry in education: Building on the legacy of Vygotsky. In C. D. Lee, \& P. Smagorinsky (Eds.), Vygotskian perspectives on literacy research (pp. 51-85). Cambridge University Press.

Yang, Y. \& Qian, D. (2020). Promoting L2 English learners' reading proficiency through computerized dynamic assessment. Computer Assisted Language Learning, 33(5-6), 628652. https://doi.org/10.1080/09588221.2019.1585882

Sean Hughes is a doctoral student in Applied Linguistics at Teachers College, Columbia University. His research focuses on language use, specifically discourse and conversation analysis. Sean's research interests are language and identity, public discourse, and embodied actions. Correspondence should be sent to E-mail: sh3936@tc.columbia.edu 